\title{
The Culture Shock and Cross-Cultural Adaptation of Chinese Expatriates in International Business Contexts
}

\author{
Ling Shi ${ }^{1} \&$ Lei Wang ${ }^{2}$ \\ ${ }^{1}$ Hangzhou College of Commerce, Zhejiang Gongshang University, China \\ ${ }^{2}$ Foreign Language Institute, Zhejiang Gongshang University, China \\ Correspondence: Ling Shi, The Foreign Language Department, Hangzhou College Of Commerce, Zhejiang \\ Gongshang University, Zhejiang, China. E-mail: shilinghelen@163.com
}

Received: October 18, 2013

Accepted: November 13, 2013

Online Published: December 23, 2013

doi: $10.5539 /$ ibr.v7n1p23

URL: http://dx.doi.org/10.5539/ibr.v7n1p23

\begin{abstract}
This thesis aims to investigate the influential causes of culture shocks experienced by Chinese business expatriates, and meanwhile to reveal their difficulties in the cross-cultural adaptation in international business contexts. The research was conducted on the base of a semi-structured interview and an on-line survey among 80 Chinese business expatriates who came from a wide range of corporations and organizations. Through a quantitative-and-qualitative analysis, eight major influential causes of culture shock were identified, namely, business communication, language, individualism, collectivism, power distance, time orientation, religion, and tradition. The study also found that all Chinese expatriates encountered some cultural shocks in international business context and were greatly affected by communication, language, religious and traditional issues. The study further revealed three major difficulties in the cross-cultural adaptation: poor adaptability of business communication, language barriers and heavy pressure from work duties. Finally, based on the findings, several effective measures for a better cross-cultural adaptation were proposed.
\end{abstract}

Keywords: culture shock, cross-cultural adaptation, business contexts, Chinese expatriates

\section{Introduction}

In the current age of economic globalization, more and more business expatriates have been sent for cross-national investment and overseas operation. However, the expatriates' adaption is not always successful in a culturally different environment, since they are supposed to adjust to both of the local working environment and the life environment, which are unusually very different and challenging. It is reported that the expatriation failure rate is estimated at $15-50 \%$, and the average estimated monetary cost of an expatriation failure is placed from \$200,000 to \$1.2 million (Selmer, 1998; Black \& Gregersen, 1999; Graf, 2004). Among the various reasons that could lead to expatriation failure, the cross-cultural factors may have contributed a large proportion. Generally, business expatriates are confronted with a new world of cultural pattern, and their main challenges compose of having to understand these different assumptions and values in the new cultural environments and to find ways to get reliable information and expertise (Black \& Gregersen, 1991b; Janssens, 1995). Due to the high frequency of expatriation failure and the associated costs, most studies on culture shock and expatriates' cross-cultural adaptation (Ward \& Kennedy, 1996; Aryee \& Stone, 1996; Shaffer \& Gilley, 1999; Selmer, 2002) are necessary, especially for the international business.

This research presents an empirical study on Chinese expatriates, and aims to answer the following questions:

- What are the influential causes of culture shocks experienced by Chinese expatriates in the international business contexts?

- What is the current condition of Chinese expatriates' cross-cultural adaptation in the international business contexts, and what are the major difficulties for them on the cross-cultural adaptation?

The paper begins with a focused literature review on the key concept "culture shock", presents the models of cross-cultural adaptation, and then explains the causes of culture shock in the cross-cultural adaptation process. Next, an empirical study based on a semi-structured interview on culture shocks and an on-line survey on Chinese expatriates' cross-cultural adaptation are conducted to find out key factors that will cause the culture shocks. Both quantitative and qualitative analyses are carried out on the data collected, followed by a tentative 
discussion of research findings. Finally, suggestions of the effective approaches are made for a better cross-cultural adaptation.

\section{Literature and Study Review}

Cultural shocks have been studied in various intercultural communication researches by many scholars. A better understanding of what is culture shock, how to adapt to an alien culture and what cause difficulties in the process of cross-cultural adaptation will serve as the guided tool for the present research.

\subsection{Culture Shock}

The term culture shock, first introduced by the anthropologist Kalervo Oberg, is defined as "the anxiety that results from losing all the familiar signs and symbols of social intercourses which include words, gestures, facial expressions, customs, or norms acquired unconsciously in the course of growing up" (Oberg, 1960). From a theoretical perspective, culture shock is described as "the stress induced by all the behavioral expectation differences and the accompanying uncertainty with which the individual must cope" (Black \& Gregersen, 1991). Furthermore, Solomon (1994) refers to culture shock as "an emotional and psychological reaction to the confusion, ambiguity, value conflicts, and hidden clashes that occur as a result of fundamentally different ways of perceiving the world and interacting socially between cultures". Therefore, culture shock means depression, serious physical reactions, anger, aggression toward the new culture, and even total withdrawal, and all these reactions would obviously hamper intercultural communication (Samover, Parter, \& Stefani, 2000).

On the whole, culture shock can be described as the anxiety or stress an expatriate feels immediately due to the unfamiliarity of social practice in the host country. A big challenge faced by expatriates is that those who are inadequately informed of the host country's culture or unaware of cultural difference are most likely to fail in the international business. Culture shock may occur at various levels such as an explosion of anger, frustration, depression, and homesickness (Black \& Gregersen, 1999; Harison, 1994).

\subsection{Cross-Cultural Adaptation}

Cross-cultural adaptation is a process of acclimatizing to the demand of a new cultural environment, which means both changing perspectives and reconciling beliefs to the host culture. It is more about sensitivity, understanding, reaction and anticipation. In general, there are four broad streams on the cross-cultural adaptation process. The most dominant over the last 30 years has been the U-curve theory of cultural adaptation (Lysgaard, 1955) that regards the starting point for an expatriate as being on a honeymoon high, followed by a bottoming out resulting from cultural maladjustment and finally a climb up and out to cultural acceptance and adaptation. In contrast to the U-curve model, cross-cultural adaptation is essentially conceptualized as a learning process with a classic arithmetical learning curve, which means that expatriates are initially very ignorant of the new behavioral and cultural norms and must acquire the socio-cultural skills both by learning new culture and participating (Taylor, 1994). The third approach describes the cross-cultural process as the culture adaptation of learning and recovery from ethnocentrism to ethno-relativism, which means that an expatriate experiences a step-by-step psychological journey from the periphery of a culture to the centre, from a state of ignorance and resentment to a position of understanding and empathy. The fourth approach considers the cross-cultural adaptation as a dynamic and cyclical process of tension reduction, which is also defined as a homeostatic mechanism model (Chapdelaine $\&$ Alexitch, 2004).

With the recognition of the complex process of cross-cultural adaptation, such important elements as individual adaptation strategies, cognitive factors and the facts that people thrive on stress are further studied. Redmond and Bunyi (1993) offer a communication model which focuses on intercultural communication competence. Gabel (2005) investigates the importance of Emotional Intelligence in shaping the expatriate's cross-cultural adaptation competence. Davis (2001) suggests six stages of cross-cultural adaptation process, namely, excitement, confusion, frustration, effectiveness, appreciation, increased cross-cultural competence. Mitchell and Myles (2010) modify the stages of cross-cultural adaptation and point out that cross-cultural adaptation should be a time-bound process to the expatriates. Though cross-cultural adaptation may be a challenging and stressful process, it is undoubtedly critical for all expatriates to succeed in the international business contexts.

\subsection{Causes of Culture Shock in the Cross-Cultural Adaptation Process}

In review of empirical researches on culture shock, Miller (1986) concluded ten causes of culture shock: climate, dressing code, language, education, eating habit, infrastructure, religious belief, entertainment, family life and courtship. Windham International (1999) identified three influential causes for "assignment failure", namely, partner dissatisfaction, family concerns, and the inability to adapt. The research also indicates that the major challenge for expatriates is to cross cultures successfully, in other words, the inability to adapt is one of the 
biggest barriers for expatriates. Most symptoms concerning the culture shock have been examined that those threats to the sensitive areas of confidence, ego, and self-esteem can cause extreme reactions related with the cross-cultural adaptation (Sappinen, 1993; Kohls, 2001). Feichtinger and Fink Adler (2003) found that the cross-culture adaptation process would prolong for a long period of time if it could not properly be dealt with the causes of culture shock. Moreover, Xia (2009) claimed the necessity for understanding cultural diversity and cross-cultural communication as a global issue in a cross-cultural adaptation process. In the recent decades, the issue of culture shock has become dominant in cross-cultural adaptation studies and has been incorporated into many pre-departure training programs for expatriates (Murdon \& Kaciak, 2011).

Besides all the studies on cross-cultural adaptation which take one or several specific factors as their subject, Ward and Kennedy (1992) made a more systematic study in which two key types of cross-cultural adaptation were presented: psychological adjustment and socio-cultural adjustment. In her study, she found that psychological adjustment was broadly affected by personality, life changes, and social support, while socio-cultural adaptation was broadly influenced by factors such as social interaction with host nationals, length of stay in a new culture, cultural identity and cultural distance (Ward \& Kennedy, 1992). Later, Ward (2001) developed a self-contained system about cross-cultural adaptation. The questionnaire developed by her, Socio-cultural Adjustment Scale (SCAS), covering both macro and micro factors in cross-cultural adaptation, has very practical meaning for cross-cultural adaptation.

However, in most researches on culture shock, the body of literature review seems anecdotal or descriptive in nature. The concept of culture shock is often mentioned tangentially, as part of the broader topic of expatriates' cross-cultural adaptation (Munford, 1998). Furthermore, many studies on cross-cultural adaptation stress the importance of the communication ability in a culturally appropriate way. Taking the implications of culture shock and cross-cultural adaptation into consideration, it is somewhat surprising that there are few empirical studies on the expatriates' experience of culture shock or the difficulties expatriates encountered in the cross-cultural adaptation process.

\section{Methodology}

The main objective of this study is to identify influential causes of culture shocks experienced by Chinese business expatriates, and further to reveal their difficulties in cross-cultural adaptation in the international business contexts. Figure 1 shows the research structure which consists of two major parts, the semi-structured interview and the on-line questionnaire. As is presented, the research structure is designed with the theoretical

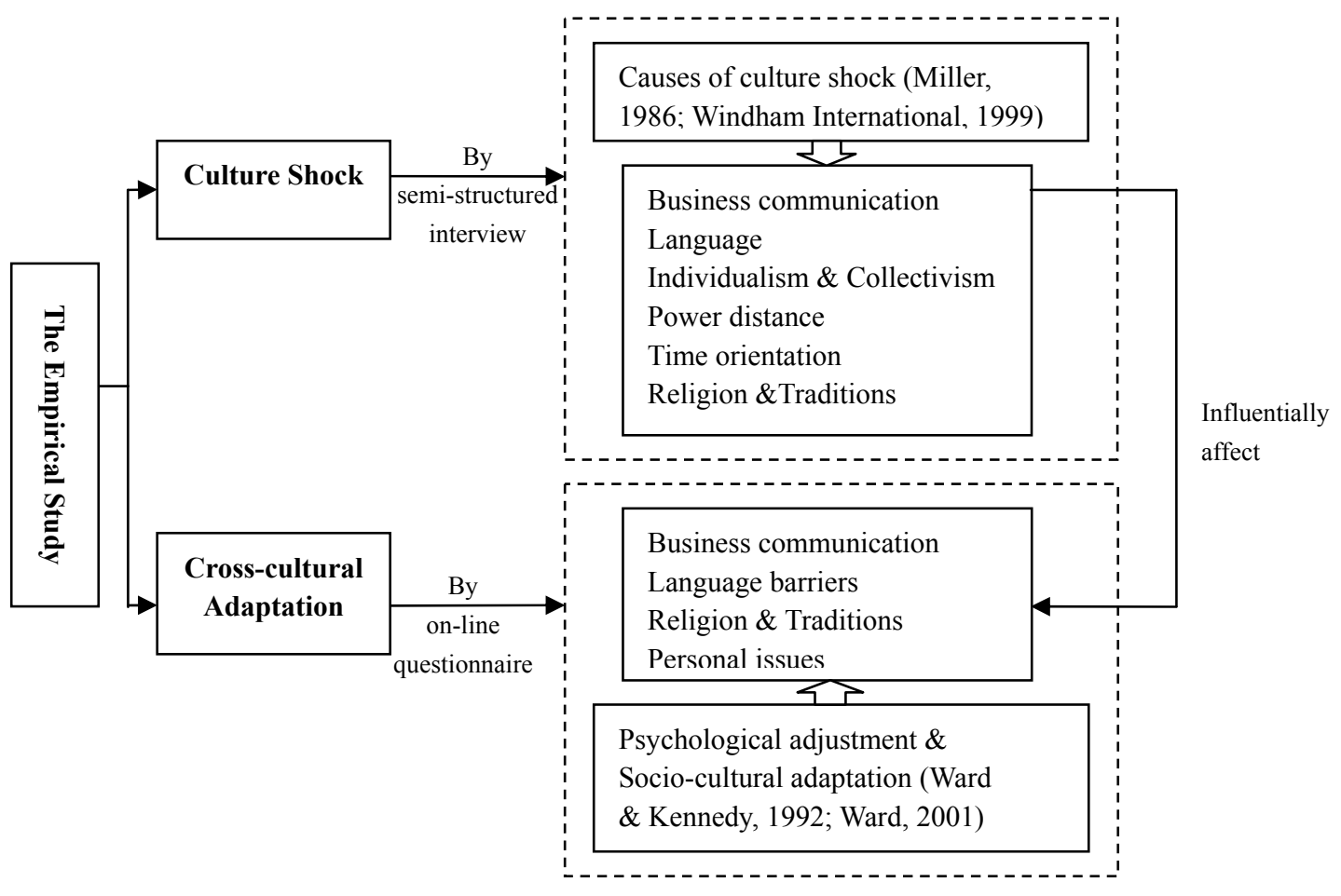

Figure 1. Research structure 
basis of studies on causes of culture shock (Miller, 1986; Windham International, 1999) and Ward's study on psychological adjustment and socio-cultural adaptation (Ward \& Kennedy, 1992; Ward, 2001). Because there are numerous causes which can exert influences on cross-cultural adaptation, this thesis focuses on several influential ones in the discussion. Accordingly, the semi-structured interview was conducted as a pilot investigation with the purpose of finding out major influential causes of culture shocks. Based on the interview, an on-line survey with the questionnaire was further carried out to investigate the current condition and difficulties met by Chinese expatriates' in their cross-cultural adaptation.

The respondents were chosen from a wide range of corporations and organizations to reflect the true international business contexts. All the respondents in the survey were Chinese business people who were once expatriates or who were experiencing a cross-cultural assignment at the time when the survey was conducted. Also, an attempt was made to have a broad distribution across the demographic categories of gender, age, and education. In the pilot interview section, 15 respondents participated in the research, and with their consent, they were asked whether they had met with culture shock in the international business, and were also allowed to reflect upon the incidents of culture shock in the host country. In the on-line questionnaire section, totally 80 respondents participated in the research, and finally 63 eligible questionnaires were obtained, which accounted for $78.75 \%$ response rate.

Considering that all respondents were Chinese, both of the interview and the online questionnaire were made in Chinese version to help them with a better understanding of each item in the survey. The questionnaire was focused on the cross-cultural adaptation process and designed on the base of the findings in the interview part and the studies on the psychological and socio-cultural adjustment (Ward \& Kennedy, 1992; Ward, 2001). It included two major sections. The first section of personal data concerned about demographic information such as gender, job position, age, expatriation experience, length of stay and etc. And the second section of cross-cultural adaptation process covered several key internal and external cultural factors and personal factors, including: business communication, language barriers, religion \& traditions, and personal issues. All questions were rated by the five-point Lickert-type scale with five standing for well adjustment (see Appendix II).

\section{Findings and Discussion}

\subsection{Major Causes of Culture Shocks: Interview}

Respondents in this research were all personally influenced by culture shocks in different host countries. Based on the interview, we built eight major causes of culture shocks listed as follows: business communication, language, individualism, collectivism, power distance, time orientation, religion and traditions. By comparison, we found four causes, communication, language, religious and traditional issues, affected the respondents greatly in expatriation, while causes such as power distance, individualism and collectivism didn't affect them much (See Figure 2, and Appendix I).

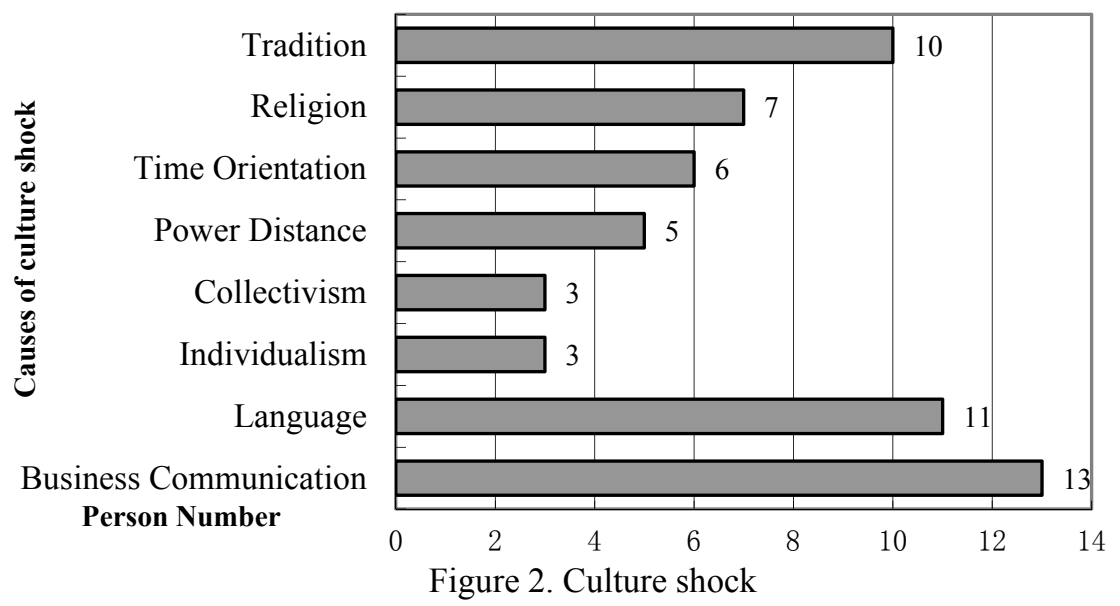

According to Figure 2, the study highlighted the problems on communication and language in cross culture. In the pilot interview, a majority of respondents talked about their culture shock experience in communication, language, tradition and religion, among which business communication ranked first $(\mathrm{N}=13)$, language ranked second $(\mathrm{N}=11)$, tradition ranked third $(\mathrm{N}=10)$, and religion ranked fourth $(\mathrm{N}=7)$. Specifically, the issues of 
misunderstanding, words confusion, grammatical mistakes, thinking modes, personal spaces, eye contact, and straightforwardness in communication were frequently mentioned by the respondents. Moreover, it also confirmed that cross-cultural communication in the high context differed from that in the low context. For example, in those low-context countries such as Germany and U.S., verbal language and explanations appeared to dominate in the business communication, whereas in those high-context countries such as Japan and Singapore, body language and facial expression were paid more attention to in the business context.

It was also found from each cause that religion and traditions represented two key issues to affect the expatriates' cross-culture adaptation, as two causes were highly related. In the interview, many respondents mentioned about their overseas experience concerning with different religions, most of which were positive to their cross-cultural adaptation. It was perceived that behavioral gap from different religion and tradition might explain the current difficulties in cross-cultural adaptation. Though many culture shocks were resulted from the differences between Chinese Confucianism and the western culture, it was found from the interview that Chinese expatriates were interested in dealing with those culture shocks and regarded them as their amazing experiences.

Regarding time orientation $(\mathrm{N}=6)$, some respondents mentioned that they felt a bit frustrated with working efficiency in certain host countries, for instance, Russia, Brazil and Arab countries. In contrast, in those western-cultural countries as UK, Germany and U.S., emphasis on the efficient use of the time to accomplish tasks brought the working pressure to expatriates, but on the other hand, it positively encouraged a better cross-cultural adaptation for them in the business contexts.

\subsection{Findings on Difficulties in Cross-Cultural Adaptation: Questionnaire}

Based on the findings of both the culture shock interview and the studies on the psychological and socio-cultural adjustment (Ward \& Kennedy, 1992; Ward, 2001), the on-line questionnaire (see Appendix 2) on the cross-cultural adaptation was finally made to cover four major aspects including 14 items, with the purpose to further investigate the current condition and difficulties of Chinese expatriates' cross-cultural adaptation. Both the collected data and results from the quantitative analysis are listed as follows (see Figure 3 and Table 1).

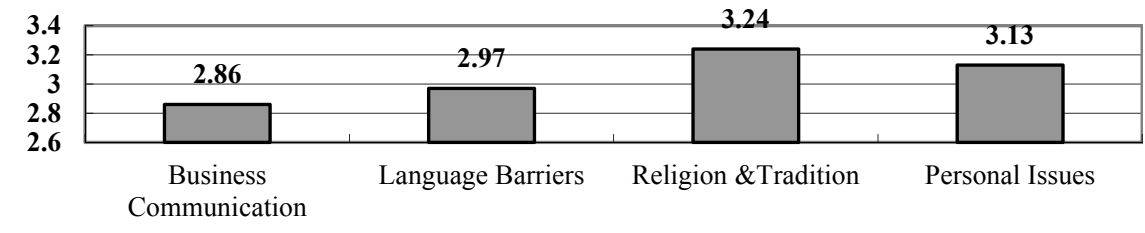

Figure 3. Cross-cultural adaptation

Table 1. Cross-cultural adaptation level of Chinese expatriates

\begin{tabular}{|c|c|c|c|c|}
\hline Categories & Items & Mean & SD & Mean in Total \\
\hline \multirow{4}{*}{ Business Communication } & Business presentation/reports & 3.71 & 0.847 & \multirow{4}{*}{2.86} \\
\hline & Difference in communication style & 2.46 & 0.866 & \\
\hline & Difference in business management & 2.29 & 0.885 & \\
\hline & Understanding of faculty staff & 3.00 & 0.921 & \\
\hline \multirow{4}{*}{ Language Barriers } & Understanding social language & 3.45 & 0.952 & \multirow{4}{*}{2.97} \\
\hline & Speaking in business conference & 2.20 & 0.899 & \\
\hline & Reading business documents & 3.25 & 0.879 & \\
\hline & Writing business reports & 3.00 & 0.902 & \\
\hline \multirow{4}{*}{ Religion \& Tradition } & Tradition & 3.89 & 0.543 & \multirow{4}{*}{3.24} \\
\hline & Religious concerns & 3.72 & 0.687 & \\
\hline & Racism & 2.50 & 0.816 & \\
\hline & Time orientation & 2.85 & 1.034 & \\
\hline \multirow{2}{*}{ Personal Issues } & Loneliness/ isolation & 3.50 & 0.895 & \multirow{2}{*}{3.13} \\
\hline & Pressure from work duties & 2.75 & 1.237 & \\
\hline
\end{tabular}


Both Table 1 and Figure 3 showed the cross-cultural adaptation level of Chinese expatriates in the international business context. According to the statistics, business communication and language barriers were two major difficulties in cross-cultural adaptation for Chinese expatriates, since the adaptation level of business communication was $2.86(\mathrm{M}<3$, this meant "relatively difficult" in rating scale) and the adaptation level of language barriers was $2.97(\mathrm{M}<3)$. The findings were consistent with the results from the pilot interview on culture shocks.

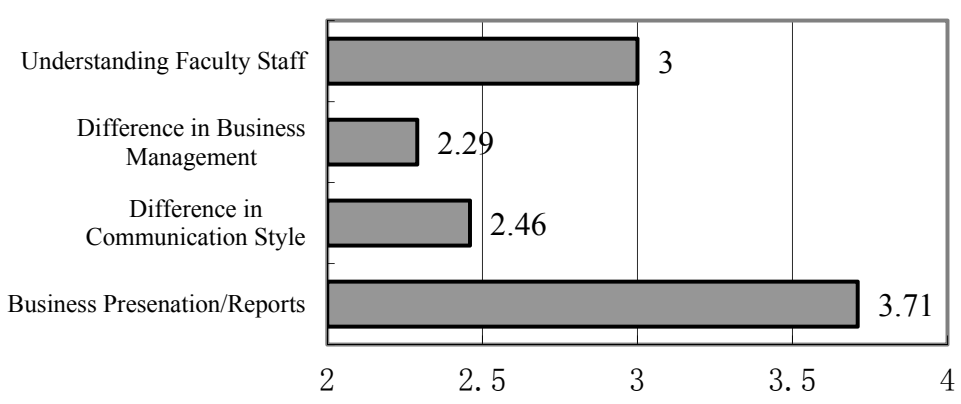

Figure 4. Business communication

Precisely, in the aspect of business communication, Figure 4 showed that most expatriates felt inadequate in dealing with different communication style $(\mathrm{M}=2.36<2.5$, this meant "very difficult" in rating scale) and also considered themselves to be weak in adapting to different business management $(\mathrm{M}=2.79<3)$.

Furthermore, in the aspect of language barriers, Figure 5 showed that speaking in business conference was the most difficult $(M=2.21<2.5)$, while the means of the other three items, understanding social language, reading business documents and writing business reports were all above 3, indicating Chinese expatriates had the general language competence and they were likely to have taken certain language training courses before going abroad.

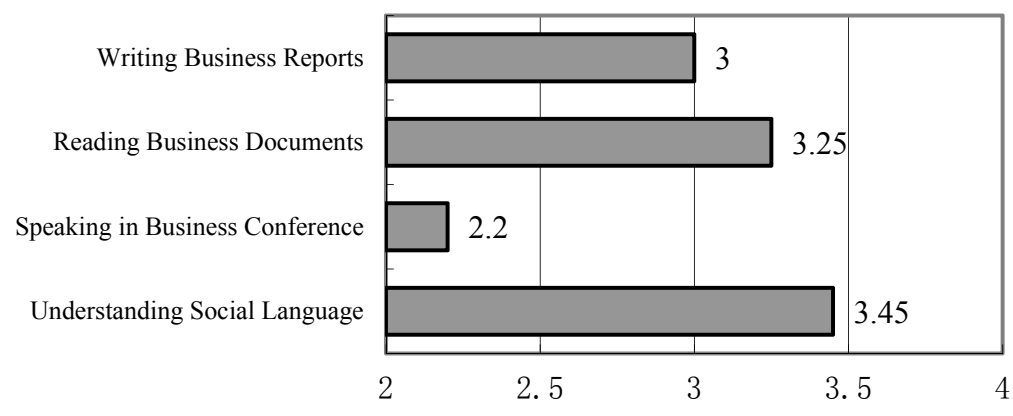

Figure 5. Language barriers

In the aspect of religion and tradition, Figure 6 clearly showed that most respondents had been influenced by racism and time orientation at work and had a sense of being deeply uncomfortable, as both means of the two items were below 3 . As was discussed above in the pilot interview section, though culturally different, most expatriates had a fairly good adaptability to local religion and tradition. According to statistics, the mean of religious concerns was 3.72 , and the mean of tradition was 3.89 .

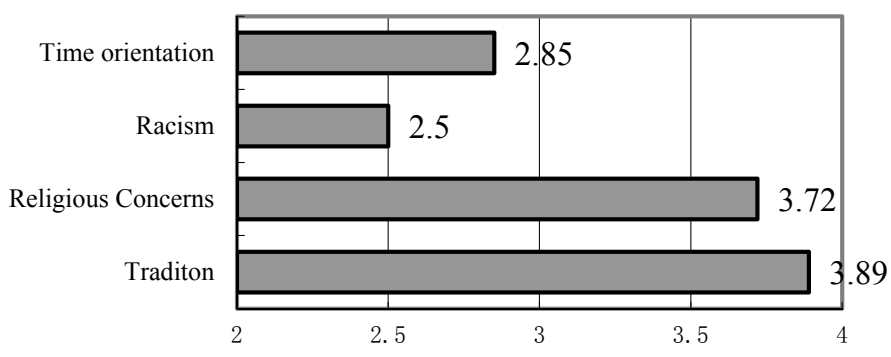

Figure 6. Religion \& Tradition 
Regarding to the personal issues, the study found that many expatriates suffered from a heavy pressure from their work duties $(M=2.75<3)$, though the reasons were very complicated. In all, based on the statistic analysis, major factors accounted for the Chinese expatriates' difficulties in cross-cultural adaptation: poor adaptability of business communication, language barriers and heavy pressure from work duties.

\subsection{Business and Managerial Implications}

As the cross-cultural adaptability surely influences the expatriate's job performance, the international corporation should offer and the expatriates themselves should take an active participation in cross-cultural adaptation training which may highlight the target culture in the host country. The researching findings indicated that corporations are suggested to take some preventative steps to help expatriates overcome their difficulties in the cross-cultural adaptation, which will, in return, effectively avoid the possible business expatriation failure.

First of all, both of the pre-departure training and the post-departure training should be provided. Since poor adaptability of business communication is one of the major difficulties of cross-cultural adaptation, a range of culture courses in terms of business communication and management should be provided to help expatriates equip with cross-cultural communication skills. At a minimum the following aspects are highly recommended in the pre-departure training program (Bennett, Astom, \& Colquhoun, 2000):

1) General and country-specific cultural awareness,

2) Frameworks for understanding and valuing cultural differences,

3) Planning for a successful international assignment,

4) Cross-cultural business skills for working effectively in the international business context,

5) Understanding cultural variations for those with regional responsibilities,

6) Business and social customs in the host country,

7) International transition and stress management,

8) Practical approaches to culture shock management and life-style adjustment.

The research findings told us that language barriers matter much in the process of cross culture adaptation. Thus, the language training should also be a priority. Such training must aim at enhancing the expatriates' language competence, both speaking and writing skills. Then, professional cross-cultural adaptation training should be continuously given even after the expatriate's arrival at the host country, because the pre-departure training can provide expatriates with the knowledge only to survive rather than to excel cross-culturally. Pause in training were the possible reasons why most expatriates still felt incompetent in dealing with the different time orientation and racism even though they accepted the pre-departure training on cross-culture. As matter of fact, during the international business contexts, expatriates encounter specific situation to which no clear answer is given in the pre-departure training (Mendenhal \& Stahl, 2000). This is what makes the post-departure training essential and appropriate. Accordingly, the post-departure training should at least contain in-depth language training besides the basic knowledge learned in the pre-departure training phases, and should also focus on the improvement of the cross-cultural adaptability. It is the responsibility of the international corporation to offer the research programs on cultural adaptation and provide potential expatriates with helpful consultant services to ensure that they will not feel isolated in a foreign culture. To help with specific cross-cultural problems in the international business context, the real-time training is highly suggested as an effective approach to facilitate cross-cultural adjustment. The real-time training deals with high individualization, task-orientation, confidentiality, and the easy transfer of newly acquired skills to the new situation (Bennett, Astom, \& Colquhoun, 2000).

Secondly, the results from the interview and on-line questionnaire indicate that corporations should give assessment on cross-cultural adaptability to test whether expatriates have the qualified competence. Such assessment will also provide feedback for further training sessions.

Thirdly, it is perceived from the present research, that the emotional intelligence is another significant factor which deeply influences the expatriate's adaptability to the host culture. As is reported, expatriates with high emotional intelligence usually have better relations with their foreign colleagues, and are more capable of taking the appropriate measures to better tackle the challenging situations.

As for the business expatriates, it is essential for them to raise their cross-cultural adaptability, which means they should learn form their experiences and use new experiences to improve the inter-personal relationships. Business expatriates need to be more open to various customs, values and social practice of the host culture, and 
take the initiative to interact with host nationals. Only in that way, can they reduce conflicts and misunderstandings in the new cultural environment and finally adapt to it. In order to keep a harmonious working atmosphere, establishing a good relationship with foreign colleagues is more than necessary. Additionally, improving target language competence and learning some knowledge on social etiquettes also contribute a lot to a better job performance and cross-cultural adaptation.

\section{Conclusion}

This paper identified major influential causes of culture shocks experienced by Chinese business expatriates, and further revealed their difficulties in cross-cultural adaptation in international business contexts. The study emphasized the importance to understand cultural shocks and the necessity to improve the cross-cultural adaptability for the effective performance on the international business. In the host culture, Chinese expatriates should always be ready to face the challenges from communication gap, language barrier, different tradition and religious practices. As a result, the sufficient cross-cultural adaption training provided by international corporations becomes very essential.

The generalizations of the finding from this study were limited to sample groups. Although a great deal of effort was expended to insure the reliability of this research, there are a few limitations to this study.

First, since the on-line questionnaire is self-reported, the data collection was only limited to the expatriates themselves, whereas the evaluation either from their family members or colleagues was not included. Second, this study was unable to provide a longitudinal account of expatriates' cross-cultural adaptation due to the cross-sectional design, only measures of a certain point in time were used in this study. Yet, expatriate adjustment and the cross-cultural adaptation are considered to be a time-related process (Black \& Mendenhall, 1991; Ward et al., 1998). A longitudinal design is important because the certain predictors may vary in time and some causes can be more important at the onset of the expatriation than later during the expatiation. Therefore, a longitudinal approach may produce a more rich data source where influential causes of culture shock and difficulties in cross-cultural adaptation could have been identified thoroughly. Finally, this study only focused on several influential factors in the cross-cultural adaptation process, while expatriate's adjustment and their cross-cultural adaption process could be influenced by many additional factors (Wards, 2001; Bhaskar-Shrinivas et al., 2005). Future research should be conducted to concern more influential factors.

Despite the limitations discussed above, the present study sheds some interesting light onto the complexity of culture shock and expatriates' cross-cultural adaptation, and underscores the need for more empirical researches in this area.

\section{Acknowledgements}

We would like to thank two anonymous reviewers for their valuable comments regarding earlier versions of this manuscript. Also we would sincerely appreciate the cooperation from all business expatriates who participated in the surveys.

\section{References}

Aryee, S., \& Stone, R. J. (1996). Work experience, work adjustment and psychological well-being of expatriate employees in Hong Kong. International Journal of Human Resource Management, 7(1), 150-164. http://dx.doi.org/10.1080/09585199600000122

Bennett, R., Aston, A., \& Colquhon, T. (2000). Dross-cultural training: A critical step in ensuring the success of international assignments. Human Resource Management, 39(2), 239-250.

Bhaskar-Shrinivas, P., Harrison, D. A., Shaffer, M. A., \& Luk, D. M. (2005). Input-based and time-based models of international adjustment: Meta-analytical evidence and theoretical extensions. Academy of Management Journal, 48(2), 257-281. http://dx.doi.org/10.5465/AMJ.2005.16928400

Black, J. S., \& Gregersen, H. B. (1991a). When Yankee comes home: Factors to expatriates and spouse repatriation adjustment. Journal of International Business Studies, 22(4), 671-694. http://dx.doi.org/10.1057/palgrave.jibs.8490319

Black, J. S., \& Gregersen, H. B. (1991b). Antecedents to cross-cultural adjustment for expatriates in Pacific Rim assignments. Human Relation, 44(5), 497-515. http://dx.doi.org/10.1177/001872679104400505

Black, J. S., \& Gregersen, H. B. (1999). The right way to manage expatriates. Harvard Business Review, 77(2), $52-63$.

Chapdelaine, R. F., \& Alexitch, L. R. (2004). Social skill difficulty: Model of culture shock for international 
graduate students. Journal of College Student Development, 45(2), 167-184. http://dx.doi.org/10.1353/csd.2004.0021

Feichtinger, C., \& Fink, G. (1998). The collective culture shock in transition countries-theoretical and empirical implications. Leadership \& Organization Development Journal, 19(6), 302-308. http://dx.doi.org/10.1108/01437739810240821

Gabel, R. S., Dolan, S. L., \& Cerdin, J. L. (2005). Emotional intelligence as predictor of cultural adjustment for success in global assignments. Career Development International, 10(5), 375-395. http://dx.doi.org/10.1108/13620430510615300

Graf, A. (2004). Expatriate selection: An empirical study identifying significant skill profiles. Thunderbirds International Business Review, 46(6), 667-685. http://dx.doi.org/ 10.1002/tie.20030

Janssesns, M. (1995). Intercultural interaction, a burden on international managers. Journal of Organizational Behavior, 16, 155-167. http://dx.doi.org/ 10.1002/job.4030160206

Kohls, L. R. (2001). Survival kit for overseas living: For Americans planning to live and work abroad. Yarmouth, ME: Intercultural Press.

Lysgaar, S. (1955). Adjustment in a foreign society: Norwegian Fulbright grantees visiting the Untied States. International Social Science Bulletin, 7, 45-51.

Mendenhall, M. E., \& Stahl, G. K. (2000). Expatriate training and development: Where do we go from here? Human Resource Management, 39(2), 251-263. http://dx.doi.org/10.1002/1099-050X(200022/23)39:2/3<251::AID-HRM13>3.0.CO;2-I

Mumford, D. B. (1998). The measurement of culture shock. Journal of Social Psychiatry \& Psychiatric Epidemiology, 33, 149-154. http://dx.doi.org/10.1007/s001270050037

Murdoch, A., \& Kaciak, E. (2011). Culture Shock Re-visited: What features of the Polish culture most bother expatriates in Poland? Journal of Applied Business Research, 27(2), 87-104.

Oberg, K. (1960). Culture Shock: Adjustment to new cultural environment. Practical Anthropology, 7, 177-182.

Redmond, M., \& Bunyi, J. (1993). The relationship of intercultural communicative competence with stress and the handling of stress as reported by international students. International Journal of Intercultural Relations, 17, 235-254. http://dx.doi.org/10.1016/0147-1767(93)90027-6

Sappinen, J. (1993). Expatriate adjustment to foreign assignment. European Business Review, 93(5), 3-11. http://dx.doi.org/10.1108/EUM0000000001922

Selmer, J. (1998). Expatriation: Corporate policy, personal intentions and international adjustment. The International Journal of Human Resource Management, 9(6), 996-1007. http://dx.doi.org/10.1080/095851998340711

Selmer, J. (2002). Practice makes perfect? International experience and expatriate adjustment. Management International Review, 42(1), 77-87.

Shaffer, M. A., Harrison, D. A., \& Gilley, K. M. (1999). Dimensions, determinants, and differences in the expatriate adjustment process. Journal of International Business Studies, 30(3), 557-581. http://dx.doi.org/10.1057/palgrave.jibs.8490083

Solomon, C. M. (1994). Success abroad depends on more than job skills. Personnel Journal, 4, 51-59. http://dx.doi.org/10.1108/01437720010377837

Taylor, E. (1994). A learning model for becoming inter-culturally competent. International Journal of Intercultural Relations, 18(3), 389-408.

Ward, C., Bochner, S., \& Furnham, A. (2001). The Psychology of Culture Shock (2nd ed.). Philadelphia: Taylor $\&$ Francis.

Ward, C., \& Kennedy, A. (1992). Locus of control, mood disturbance and social difficulty during cross-cultural transitions. International Journal of Intercultural Relations, 16, 175-194. http://dx.doi.org/10.1016/0147-1767(92)90017-O

Ward, C., \& Kennedy, A. (1996). Crossing cultures: the relationship between psychological and socio-cultural dimensions of cross-cultural adjustment. In Pandey, J., Sinha, D., \& Bhawuk, D. P. S. (Eds.), Asian Contributions to Cross-cultural Psychology. New Delhi: Sage Publications. 
Ward, C., Okura, Y., Kennedy, A., \& Kojima, T. (1998), The U-curve on trial: A longitudinal study of psychological and socio-cultural adjustment during cross-cultural transition. International Journal of Intercultural Relations, 22(3), 277-291.

Xia, J. (2009). Analysis of impact of culture shock on individual psychology. International Journal of Psychological Studies, 1(2), 97-101.

Appendix I. Interview on culture shock

\begin{tabular}{|c|c|c|}
\hline Categories & Host country & Summary of main event experienced in the host country \\
\hline \multirow{4}{*}{ Business communication } & Russia, UK, U.S. & Language misunderstandings in business context \\
\hline & Japan & The importance of wide personal space \\
\hline & Oman & Direct eye contact when speaking and greeting \\
\hline & U.S & Straightforwardness \\
\hline \multirow{3}{*}{ Language } & Germany & People rarely speaking English even if they know it \\
\hline & USA, UK & Words confusion \\
\hline & Russia & Grammatical mistake \\
\hline \multirow[t]{2}{*}{ Power distance } & UK & $\begin{array}{l}\text { Manager visits his employees to assign them a task and even waits to talk to them if they } \\
\text { are busy on the phone }\end{array}$ \\
\hline & Russia & Business appointment should be made in advance with secretary \\
\hline \multirow{2}{*}{ Time orientation } & Arab countries & Arriving half an hour late for a meeting but people beginning without her \\
\hline & Japan, German & All things are arranged accurately on time. \\
\hline Individualism & Canada & No one greeting a new comer \\
\hline \multirow[t]{2}{*}{ /Collectivism } & Russia & Indifferent to new comer \\
\hline & Russia, Arab & Uncomfortable racism \\
\hline Religions & $\begin{array}{l}\text { Russia, Germany, } \\
\text { Arab }\end{array}$ & Believe " Evil with evil" \\
\hline \multirow[t]{4}{*}{ Tradition } & Oman & The weekend being Thursday and Friday \\
\hline & Germany & Strict work style \\
\hline & USA & Hugging to show the friendliness \\
\hline & Russia & Slow pace of life \\
\hline
\end{tabular}


Appendix II: On-line Questionnaire

Questionnaire on Chinese Expatriates' Cross-cultural Adaptation in International Business Context

\section{Demographic information}

Gender: $\square$ Male

$\square$ Female

Age: $\square 20-30 \quad \square 31-40$

$\square 41-50 \quad \square$ above 50

Countries of Expatriation:

Length of Stay:

\section{Cross-cultural Adaptation in International Business Context}

Please evaluate your cross-cultural adaptation level based on expatriation experience.

1-very difficult and not adjusted at all; $\quad 2$-a bit difficult and not well adjust;

3-neutral; $\quad 4$-a bit easy and adjusted; $\quad 5$-very easy and well adjusted

\begin{tabular}{lll}
\hline Categories & Items & $\begin{array}{c}\text { Cross-cultural } \\
\text { Level }\end{array}$ \\
\hline & Business presentation/reports & Adation \\
Business Communication & Difference in communication style & Difference in business management \\
& Understanding of faculty staff & \\
\hline Language Barriers & Understanding social language \\
& Speaking in business conference \\
& Reading business documents \\
& Writing business reports \\
\hline Religion \& Tradition & Tradition \\
& Religious concerns \\
& Racism \\
\hline Personal Issues & Time orientation \\
\hline
\end{tabular}

\section{Copyrights}

Copyright for this article is retained by the author(s), with first publication rights granted to the journal.

This is an open-access article distributed under the terms and conditions of the Creative Commons Attribution license (http://creativecommons.org/licenses/by/3.0/). 